\title{
Urucungo. Poemas negros: ¿entre negrismo y negritud?
}

Urucungo. Black Poems: Is it Between Negrismo and Negritude?

Urucungo. Poemas negros: entre negrismo e negritude?

\section{Laura Masello}

UNIVERSIDAD DE LA REPÚBLICA, MONTEVIDEO, URUGUAY

Profesora de la Universidad de la República, Montevideo. Doctora en

Ciencias del Lenguaje, Universidad Nacional de Córdoba, Argentina.

Autora de Lenguas en la región: enseñanza e investigación para

la integración desde la universidad (Mastergraf, 2012), El revés de

la trama: escrituras identitarias en Brasil y el Caribe (Biblioteca

Plural, 2011). , La traza y la letra (Comisión Sectorial de Investigación

Científica, en prensa). Correo electrónico: lmasello@gmail.com

Artículo de reflexión

Documento accesible en línea desde la siguiente dirección: http://revistas.javeriana.edu.co

doi: 10.11144/Javeriana.cl19-38.upnn 


\section{Resumen}

Raul Bopp se vuelca hacia la temática negra en Urucungo después de haber explorado el universo amazónico en Cobra Norato en el intento de redescubrimiento de las raíces que caracterizó al movimiento antropofágico. En este trabajo exploramos si su propuesta se inscribe dentro del concepto de negritud césairiana, como expresión de la voluntad de pertenecer a África; si se adscribe a una apología de la raza negra como respuesta política al blanqueamiento impuesto por los grupos hegemónicos después de la abolición; o si permanece en los moldes del "negrismo estetizante de los años 20", constituyendo el espejo brasileño de "un repertorio producido por una élite artística blanca y europea" (Schwartz, Las vanguardias 1991, 617-618).

Palabras clave: negrismo; negritud; antropofagia

\section{Abstract}

Raul Bopp delves into black themes in Urucungo, after having explored the Amazonian universe in Cobra Norato in an attempt to rediscover the roots that characterized the anthropofagic movement. This essay will explore whether his proposal fits within the Césarian concept of negritude, meaning a partly political expression of an intent to belong to Africa; whether it adheres to an apology of the black race as a political response to the whitenization certain hegemonic groups imposed after the abolition of slavery; or whether it remains within the framework of the "aestheticizing negrism of the 1920s", thus becoming the Brazilian mirror of a "repertoire produced by an artistic elite that is white and European" (Schwartz, Las vanguardias 1991, 617-618).

Keywords: negrism; negritude; anthropofagy

\section{Resumo}

Raul Bopp vira para a temática negra em Urucungo depois de ter explorado o universo amazônico em Cobra Norato no intento da redescoberta das raízes que caracterizou o movimento antropofágico. Neste trabalho exploramos se sua proposta está inscrita dentro do conceito de negritude césairiana, como expressão da vontade de pertencer à África; se adscreve a uma apologia da raça negra como resposta política ao branqueamento imposto pelos grupos hegemónicos depois da abolição; ou se permanece nos moldes do "negrismo estetizante dos anos 20, constituindo o espelho brasileiro de "um repertorio produzido por uma elite artística branca e europeia" (Schwartz, Las vanguardias 1991, 617-618).

Palavras-chave: negrismo; negritude; antropofagia

RECIBIDO: 7 DE JUNIO DE 2014. ACEPTADO: 22 DE JULIO DE 2014. DISPONIBLE EN LÍNEA: 1 DE JULIO DE 2015

Cómo citar este artículo:

Maselo, Laura. "Urucungo. Poemas negros: ¿entre negrismo y negritud?". Cuadernos de

Literatura 19.38 (2015): 159-170. http://dx.doi.org/10.11144/Javeriana.cl19-38.upnn 
DURANTE EL PERÍ O D O comprendido entre las décadas de 1920 y 1930 surgieron en varios lugares de América Latina manifestaciones artísticas y literarias que tomaban por primera vez como motivo el tema del negro, mientras se creaba el espacio para la eclosión de movimientos ideológicos en torno a la problemática de su integración en las sociedades americanas, tales como la Negritud o el Renacimiento de Harlem. Era la época de descubrimiento por parte de las vanguardias europeas del arte africano que, junto al folclore y a la etnografía, cumplirían un papel relevante en la definición de las estéticas modernas (Candido 121). Pero tanto el primitivismo como la valoración del negro adquirieron significaciones diferentes en Europa y en América Latina. El término negritud fue introducido por Aimé Césaire en la revista $L$ "étudiant $N$ oir en 1934 con la intención desafiante de invertir las connotaciones ofensivas que se asociaban a la palabra negro. Se distingue de los movimientos europeos en la medida en que sus representantes (Aimé Césaire en Martinica,Jacques Roumain en Haití, Nicolás Guillén en Cuba, entre otros) crearon una literatura de identificación "a partir de experiencias existenciales del par clase/raza" (Depestre 33).

Mientras la negritud de Césaire apuntaba a que los antillanos aceptaran su herencia africana, hasta entonces renegada por ellos, exaltando y asumiendo los valores negros de la cultura trasplantada en un "retorno al país natal", no existió un movimiento literario equivalente en Brasil: "Paradójicamente, dado el altísimo componente negro del país, la moda negrista parisina y el Harlem Renaissance de los años veinte no tienen en la literatura brasileña un papel determinante" (Schwartz, Las vanguardias 151). Sin embargo, el modernismo trajo consigo la ruptura con la ignorancia o la idealización de que habían sido objeto hasta ese momento el mulato y el negro, re-significándolos como representantes visibles y cotidianos de las mismas culturas primitivas que las vanguardias europeas intentaban incorporar al arte. Tanto para A. Candido (Schwartz, Las vanguardias 121) como para J. P. Paes (103), los elementos primitivos o negros reivindicados por la vanguardia parisina, hastiada de los valores occidentales y en busca de lo exótico, en realidad guardaban una relación más coherente con la herencia cultural brasileña que con la del viejo continente.

El negro empieza a aparecer entonces en la pintura de artistas como Tarsila de Amaral o de Lasar Segall. Se realiza el Primer Congreso afro-brasileño en 1934. El año 1933 marca un punto importante en cuanto a la producción literaria: es el año de la publicación del ensayo de Gilberto Freyre "Casa-grande \& senzala" y del único libro de poesía negra de aquel momento, Urucungo. Poemas negros de Raul Bopp, como señala J. Schwartz (Las vanguardias 151). Bopp se vuelca hacia la temática negra después de haber explorado el universo amazónico en Cobra 
Norato (1931) en el intento de redescubrimiento de las raíces que caracterizó al movimiento antropofágico. Si bien Urucungo aparece como una obra aislada, no es casualidad que surja exactamente en la misma época que las obras de los autores de la negritud caribeña, por ejemplo. Cabe preguntarse entonces si se inscribe dentro del concepto de negritud césairiana, como expresión de la voluntad de pertenecer a África (una África aprendida y no vivenciada); si, como distingue R. Bastide (203), adscribe a la negritud que más tarde desarrollaría un Guerreiro Ramos en Brasil (como respuesta también política al "blanqueamiento" impuesto por los propios blancos después de la abolición), no como un retorno a África ni como apología de una cultura afroamericana sino como apología de la raza negra; o si permanece en los moldes del "negrismo estetizante de los años 20", constituyendo el espejo brasileño de "un repertorio importado, desvinculado de una realidad vivenciada $[. .$.$] producido por una élite artística blanca y europea"$ (Schwartz, Las vanguardias 617-618).

Intentaremos responder a ese planteo analizando la composición del libro Urucungo, los temas abordados y los recursos poéticos empleados por el autor como posibles caminos hacia la configuración de una posición respecto a la "cuestión del negro" (Schwartz, Las vanguardias 632).

\section{Un libro urucungo}

En la Carta que, a guisa de prólogo, Bopp dirige a Amado y Echenique, el autor destaca su preocupación por la posible recepción del libro ya que, según él, el momento no es bueno para publicar poesía. Llama la atención la insistencia con la que descalifica él mismo los versos que está presentando: "aqueles tarecos", "esses troços", "livro fácil", a la vez que expone sus intenciones respecto a la composición del libro en una suerte de partitura en cuatro secciones.

De acuerdo con esta suerte de programa sugerido por Bopp, podríamos reagrupar los poemas de la siguiente manera:

1. "África prehistórica": Casos da negra velha, África, Mãe-preta, Diamba

2. "África sexual": Dona Chica, Mucama

3. "África mística": Caratetua

4. "Cativerio, troços de lavoura, etc.": Negro, Serra do Balalão (en parte)

5. "Coisas cabalísticas (sambas e macumbas)": Marataxo, Macapá, Coco

6. "Chorados e cata-piolhos": Cata-piolho do rei Congo, Monjolo, Vaca Cristina

No obstante, nos parece que la unidad del libro está dada también por dos elementos más. Por un lado, por el ritmo musical que impregna el conjunto, no solo en el tratamiento poético de los temas sino en la disposición de los poemas en una serie de cuadros visuales y sonoros agrupables en secuencias cinematográficas, 
dejando lugar a veces a verdaderos "toques" impresionistas y otras a una suerte de vibraciones correspondientes a los poemas donde se trata el tema de la sensualidad, pasando por intensas "batidas" donde se alude a la problemática social, sin abandonar nunca lo que Bopp llama en la Carta el "gemido de negro", melodía de fondo que él asocia a un instrumento en particular, el urucungo o berimbau, que se caracteriza por su doble naturaleza de instrumento de cuerda y percusión y produce un sonido monótono como un zumbido.

Otro elemento que podría cumplir una función generadora de la composición del conjunto es el primer poema, "Urucungo", que nos parece un texto-fuente no solo por el recurso eponímico sino por la figura central del Pai João, en torno a cuyas recordaciones se crea una atmósfera propicia al juego de la memoria, abriendo espacios para los distintos cuadros que van a desfilar ante los ojos del lector. Dadas las limitaciones del alcance de este trabajo, elegimos este poema como objeto de análisis más detallado y esbozaremos luego las bases de lo que podría ser un estudio de todo el libro.

\section{El poema-fuente "Urucungo"}

Pai João es un negro mítico que, junto a otros personajes como tia Maria o pai Joaquim, representa a los antepasados de la raza negra esclavizada, como una forma de mantener la costumbre africana muy arraigada del culto a la ancestría: tras la destrucción total de los linajes por la esclavitud, los hijos negros del Brasil rendían culto a criaturas míticas. Esta figura en particular aparece también en la obra de Jorge de Lima ("Olá! Negro!", "Pai-João", 1947). La asociación con Pai João, cuyo nombre encabeza el poema, parece haberle sido sugerida al poeta por la visión de un "preto velho" que fuma con la mirada perdida en el atardecer. La tarde es el momento mítico, el momento del cuento, el momento de la oralidad. Podría decirse que el Pai João de este poema inicial cumple en cierta medida las funciones del hablador (Colombres 133), aun cuando su palabra haya sido sustituida en el lenguaje poético por la música y las imágenes. Pareciera que estas surgieran como relatos desde la voz de la memoria y es en ese sentido que la figura del negro ocupa un primer plano en el comienzo del libro, para ser portadora de la memoria expresada a través de la palabra del poeta.

La imagen del contemplador aparece en un primer plano, concentrada en el humo del cachimbo que acompaña la meditación como único elemento dinámico que complementa la actitud estática del personaje. Mediante recursos claramente modernistas como el uso del verso libre y de elementos verbales simples, en una sintaxis entrecortada por el juego con las cesuras, se crea en la primera estrofa una estampa nostálgica, con un referente espacial preciso, el mocambo, de con- 
notaciones sociales que remiten al tiempo de la esclavitud. Este término encierra, además, sonoridades evocadoras de la lengua africana de origen, que son retomadas como ecos a lo largo de la estrofa mediante la aliteración de nasales, creando la sensación de profundidad, volcada hacia el interior y alimentada por el significado ritual del humo: as sombras afundam-se, afoga no cachimbo a lembrança. Los recuerdos y sentimientos necesitan ser ahogados porque están presentes e inscriptos para siempre en el cuerpo del negro esclavo: anos de trabalho que lhe gastaram os músculos.

Comienza de esta manera el tratamiento de una serie de mitemas, según la expresión de Colombres (136), que serán desarrollados en el poemario bajo la forma de variaciones o contrapuntos. La alusión al contexto habitacional del esclavo se completa con el otro escenario, ubicado en un segundo plano del cuadro, el largo pátio da fazend que, por contraste con el silencio y la inmovilidad del primero, es el lugar donde el cuerpo del negro puede expresarse libremente a través de la música y de la danza. Lo primero que se destaca es la plasticidad de la escena, con las figuras de los negros en movimiento, magníficamente expresada mediante dos neologismos: los gerundios umbigando y corpeando, en alusión a los gestos que componen las danzas de origen africano, tales como el encuentro de ombligos (umbigada) y el choque y ondulación de cuerpos que caracterizan a estos bailes. Sabemos de la importancia sociológica de estas formas de reunión y expresión en la situación del negro en cautiverio y cómo algunos movimientos o gestos pasaron de tener una función erótica a asumir una función social significativa de la solidaridad entre los negros. El elemento sonoro llega en segundo lugar en la estrofa, que culmina con un verso lleno de ritmo, imitando el lenguaje del tambor mediante el uso de palabras onomatopéyicas que crean el efecto de percusión: bate-bate de atabaque de batuque. La repetición de las sílabas en que aparece la consonante $\mathrm{t} y$ las palabras de origen afro incorporan al ritmo "as batidas dos tambores e as pulsações do sangue negro", si aplicamos a Bopp la observación que hiciera Bastide (53-54) en su comentario sobre el poema "Olá! Negro!" de Jorge de Lima.

En este caso, esa dança nostálgica y ese soturno bate-bate melancolizan la tarde. Colombres (130) afirma que "el lenguaje del tambor es también palabra [...] escritura perfectamente descifrable, dirigida al oído y no a la vista" y que "el ritmo de los toques no constituy(e) un puro efecto musical, sino un auxiliar imprescindible de la memoria", refiriéndose a la ayuda que proporcionaba al cuentista o hablador en el contrapunto que se lograba entre ambos. Se produciría el mismo fenómeno en este poema, donde las imágenes ocupan el lugar del relato: "Erguem-se as solidões da memoria / coisas que ficaram no outro lado do mar". 
Es este otro de los motivos líricos del poema: la evocación de la tierra de África. Sin embargo, aquí se trata de una breve alusión perifrástica, ya que el tema es apenas anunciado y será objeto de desarrollo poético en los poemas siguientes. El elemento importante aquí es el contraste, expresado en el único verso aislado -que ocupa el centro del poema-, entre el estado anímico del negro y el supuesto ambiente festivo con que se asocian tradicionalmente la danza o los tambores: Preto velho nunca mais teve alegria. La alegría es negada no solo en el momento presente sino en la proyección hacia el pasado, a partir de un hecho que no aparece mencionado y que marcó para siempre la vida del negro: el embarque en los navíos negreros. Ese momento está sugerido por las "cosas" que quedaron del otro lado del mar (libertad, familia, antepasados, vida) y el uso del pretérito perfecto como expresión de tiempo absoluto y terminado, sin necesidad de anclarlo en un referente temporal preciso, por tratarse del instante que cambió en forma definitiva el destino del negro.

A ese tiempo del dolor que parece haberse detenido en el pasado y que el grupo contrarresta mediante la danza, Pai João responde con un gesto que también pretende ser una forma de conjura: toma el urucungo para poder emitir a través de él aquellas voces remotas dejadas en África. Toda la atmósfera de nostalgia que recorre el poema se concentra en ese objeto, en una suerte de contrapunto con el fondo de los tambores. Es su manera de luchar contra el dolor, que nunca dejó de ser físico también, esta vez ya no provocado por el trabajo servil ni por los castigos corporales sino por el gesto violento con el cual el patrón lo humilló: "Dói-lhe ainda no sangue uma bofetada de nhô-branco". El verbo doer conjugado en presente concentra al inicio del verbo todo el sufrimiento y la rebeldía contenidos. La brutalidad del acto pertenece al pasado y las heridas físicas ya cicatrizaron, pero hay una violencia presente que se mantiene en la sangre, latente y amenazante mientras el cuerpo viva.

El tema del dolor mantenido vivo en la sangre funcionará como leitmotiv en el resto del libro. El carácter amenazante del sufrimiento soportado y del cuerpo como lugar de la violencia se ven reforzados por el uso de los adjetivos "lúgubre e selvagem" y la idea de prolongación indefinida del canto de los negros en el empleo del presente verbal: "a toada dos negros continua". Con esa tonada se cierra el poema en forma de estribillo, compuesto a base de onomatopeyas, entre las cuales la más conocida, que forma parte de otras expresiones idiomáticas aún vigentes, es Bumba, imitación de golpe o caída, manifestación quizá del deseo de rebelión de los negros, de esperanza en un cambio radical algún día en sus vidas. 


\section{Del "gemido de negro" a "essa sangria lírica"}

Retomamos ahora el otro elemento unificador del libro que mencionábamos más arriba: la estrecha relación entre los motivos y temas abordados y su disposición, cercana tanto al lenguaje musical como al cinematográfico. El poeta anunciaba en la carta su intención de hacer un libro "só de gemido de negro". Creemos que a esa tonalidad de fondo corresponden los poemas de evocación nostálgica del África mítica, que constituyen verdaderas variaciones de ese motivo: "Casos da negra velha", "África", "Mãe-preta" y "Diamba".

En dos de ellos es usado otro personaje del folclore esclavo, esta vez femenino, la "madre negra" o ama negra, que cumple también el papel de transmisora de historias, tarea que realiza empleando imágenes naïves y un léxico infantil, como si estos versos estuvieran destinados a un público de niños para narrar el génesis de la raza. Abundan los procedimientos prosopopéyicos, como la floresta que se embaraza o el árbol que se metamorfosea en elefante y sale corriendo, en un apunte humorístico presente también en la justificación del color de la raza negra, que se explicaría por la extensa duración de “aquela noite". El uso del deíctico remite al lector-oyente a dos planos temporales: a la noche en la cual sucedieron los hechos fantásticos narrados, pero también a esa misma noche tomada como noche mítica del origen de la raza.

El tono se va agravando, sin embargo, de un poema a otro. En "África", que sigue a "Casos da negra velha", la puesta en escena del génesis es la misma pero se explicita el carácter maternal de esa África a través de la concepción física: A floresta era um útero y el hombre contempla el fenómeno desde el lugar del miedo. En "Mãe-preta" se vuelve al tono confidencial del ama negra querida, a quien el niño solicita un cuento, cuyo tema también será el recuerdo de la vida en una África remota, esta vez con alusión concreta al momento previo al embarque de los esclavos. Se reiteran aquí las imágenes pueriles, el uso del deíctico atemporal ("naquele dia do nunca-mais") y la mención a la sangre de la negra narradora como lugar de la memoria que pugna por salir: "Acordaram-se as vozes do sangue / glu-glus de agua engasgada".

El último poema de este cuarteto sintetiza los elementos principales desarrollados en los otros tres y anunciados en Urucungo. Reaparece un "negro velho" fumando y generando recuerdos, fomentados esta vez por la maconha (diamba) y traducidos en forma de alucinación: a través del mundo auditivo se produce la entrada en otra dimensión ("O ouvido de repente parou. /Com mais uma pitada / o chão perdeu o fundo. / Negro escorregou. / Caiu no meio da África"), la del retorno al pasado africano y al nacimiento mítico del río Congo como consecuencia surrealista de la acción de cincuenta elefantes que empujan una laguna y terminan desbordándola. 
Pero este toque humorístico contrasta con la función que el río luego va a desempeñar: simboliza la sangría de esclavos, frente a la impotencia del resto de la naturaleza (aguas, estrellas) que solo puede actuar ayudando a guardar la memoria ("Então as florestas se reuniram / e emprestaram um pouco de sombras pro rio Congo dormir", metáfora retomada en otros versos del libro) o despidiendo a sus hijos negros (imagen recurrente de los "coqueiros" que "debruçaram-se na praia / para dizer adeus").

La memoria del África mítica está teñida entonces de una suave nostalgia, pero salpicada también de la memoria violenta del pasado más reciente; en esa búsqueda de recuperación de la paz de las imágenes genésicas, maternales y protectoras del continente perdido parecen imponerse las imágenes más potentes del pasado posterior relacionado con la entrada en la esclavitud. El poema "Negro", ubicado en la mitad del libro, está dirigido a una segunda persona del singular, en este caso el negro esclavizado, y comienza dramáticamente exponiendo el motivo del dolor, incorporado a la sangre, de tener que cargar con un pasado que se ignora, que no parece haber sido vivido, que nunca podrá ser reconstruido. Se suceden imágenes violentas, correspondientes a los distintos pasos que configuraban la esclavización, en una suerte de iniciación, desde la irónica primeira inscrição em baixo-relevo (que no es otra cosa que el primer chicotazo) hasta la imagen del colectivo de negros encadenados. La fuerza de ambos cuadros reside en la impresión de tiempo detenido por la intensidad de la experiencia vivida: viaje interminable en el barco en condiciones infrahumanas; llegada al infierno; visión del puerto con sus depósitos de escravos. Los signos de vida que quedan de esos cuerpos-objeto yacientes en las bodegas de los barcos o en los almacenes son los sollozos anónimos apagados por el rugido del mar y las quejas inútiles condenadas al collarete. El único consuelo es la memoria de lo perdido, "o Congo, as florestas e o mar", que subsiste en el sonido del instrumento musical: "continuam a doer na corda do urucungo".

Este instrumento encarna entonces la posibilidad de atraer la memoria aprendida, destacando el poder evocatorio y simbólico de la música, motivo lírico que aparece de manera más específica en los poemas "Marabaxo" ("Dança de negro") y "Monjolo" ("chorado do bate-pilão"). El primero retoma el tono pesimista de la evocación lúgubre del viejo, en alternancia con tres estribillos: dos recrean onomatopéyicamente el ritmo de la lengua africana y de algún instrumento de percusión; el otro contiene un mensaje alusivo a la relación amo-esclavo.

Además del efecto musical, el uso de estribillos en todos los poemas del libro de Bopp recuerda la función didáctica de las estructuras repetitivas en las literaturas orales como un recurso más en el proceso de endoculturación, señala Colombres (134-135). El único elemento diferente respecto al poema "Urucungo" se relaciona con la introducción del aspecto erótico en el baile, por la presencia de las mujeres. 
En cambio, el "chorado" describe la jornada del negro esclavo, pautada por el ritmo de trabajo visto a través de la máquina con la cual se realiza, el "batepilão", término estructurador del poema en la medida en que es usado como estribillo después de cada verso, marcando no solo el paso de las horas coincidente con el ritmo acompasado del instrumento de trabajo, sino de la distancia que se va acortando entre una vida atada a ese instrumento y la muerte. Dicha palabra también abre el juego semántico y sonoro evocador del castigo corporal, ya que el verbo bater significa golpear en portugués. El ritmo del instrumento, de la vida esclavizada, del castigo corporal no se interrumpen siquiera con la muerte, presente en el poema en forma anónima: "Quando há velório de negro/ Bate-pilão", al punto que la repetición obsesiva del mismo término con el cual se creaba la sensación sonora del paso de las horas y de los golpes en el instrumento y en el cuerpo termina convirtiéndose, al final del poema, en la resonancia de las paladas del entierro: "Negro levado `para cova / Bate-pilão".

Pero si la muerte no trae el descanso esperado, a veces conlleva la venganza a través de la figura del zombi. En Serra do Balalão, el castigo arbitrario y trágico del que es objeto un negro, acusado injustamente de haber matado al patrón y finalmente ahorcado, se revierte en la metamorfosis de la víctima, cuya zombificación determina una atmósfera de terror in crescendo que sobrepasa el marco referencial del hecho que motivó su muerte para entrar en una dimensión mítica colectiva: "Diz-que de vez em quando / ouve-se um ai-ai estrangulando-se no fundo do mato. / -Não fui eu! /E essa pancada seca/ ouve-se por todo o Brasil!"

En medio de esta melodía de fondo tan lúgubre, el poeta introduce algunos "toques" un poco menos pesimistas, como por ejemplo en Caratetua: allí presenta una escena diferente a las ya descritas, relacionada con una procesión católica en una plaza, en una polifonía en que se alternan el coro de las viejas frases aisladas de diálogos interrumpidos y el estribillo sonoro de las campanadas, interpretado como un mensaje social con cierta cuota de humor: "Quem dá, dá. Quem não dá, não tem nada o que dá", que recalca el tema de la pobreza, dentro de un cuadro de aparente armonía asegurada por el sincretismo con el blanco católico.

La figura femenina participa también de estos claroscuros contrapuntísticos. Si bien la mujer negra está asociada a lo erótico, no puede disfrutar de su sensualidad, pues es castigada brutalmente si llega a seducir, como en "Dona Chica", donde la violencia sobre la mujer negra es ejercida por otra mujer, la patrona, como represalia por haber provocado a quien no corresponde (aparentemente su marido). Sin embargo, en "Mucama", la relación ama-esclava no solamente es menos violenta (aunque el apelativo despectivo negra boba y sus variantes funcionen como estribillo descalificador por oposición a la proliferación de diminutivos 
afectuosos con los que la esclava se dirige a la patrona) sino que existe cierta complicidad sensual entre ambas mujeres y el papel de confidente que conoce los secretos amorosos y eróticos del ama confiere cierto poder compensatorio a la esclava. Compensación asociada a lo sensual o sexual que puede encontrar caminos más poderosos si se recurre al espiritismo, ya sea para conjurar el mal de ojo, como en "Coco", o para utilizar los poderes rituales de la macumba, como en "Macapá".

La sensualidad y el erotismo -"Raul Bopp no se libera completamente de los arquetípicos prejuicios relativos a la sensualidad y la indolencia de la raza negra" (Schwartz 622) - son algunos de los componentes asimismo de los dos cuadros finales de las Favelas, asociados a la modorra de la hora de la siesta, presentada de forma pictórica en estas dos "impresiones" correspondientes ahora al momento histórico del presente urbano. Ambos poemas están compuestos como secuencias de una película, con elementos plásticos (la calle que interrumpe el plano con su ondulación de costela, el efecto pictórico y humorístico de las ventanas semi-cerradas con dor-de-dente) y sensuales en la abundancia y exuberancia de la naturaleza ("Bananeira botou as tetas do lado de fora / Mamoeiras estão de papo inchado") o la presencia de la mujer seductora ("Correu um ventinho levanta-a-saia", "Passou a negrinha catonga/se rebolando toda"). No falta el elemento moderno con la presencia del tren, que produce un quiebre en esa atmósfera de exaltación de la pereza, tema caro a los autores de la antropofagia.

El libro termina con el poema "Tapuia", que no guarda aparentemente relación directa con el calificativo negro, ya que el título remite a la etnia tupí: tapuia era el término mediante el cual los indios tupís calificaban a sus enemigos. Escrito en segunda persona, se dirige a un tú femenino cuyo origen ya no es africano sino amazónico, con una sugestiva alusión a las divinidades indígenas del agua. El punto común con el resto del libro es el tema de la herencia histórica y cultural, relacionada con la búsqueda de la memoria y de las raíces. Quizá Bopp haya querido de esta manera reunir poéticamente a las dos raças anônimas provenientes de tribos desaparecidas y ligadas por el destino en la realidad brasileña, representada por as noites do Amazonas y las cinco estrelas do Cruzeiro. Como refiere Bastide (86): "Contra los mitos de la raza blanca o de la negritud, el encuentro del indio y el negro ha permitido el nacimiento de otro mito, el de la mezcla de las sangres y de la fusión de las razas".

\section{Lo negro}

En un intento por responder a la interrogante que propusimos en la introducción de nuestro trabajo, podemos decir que, si bien Urucungo propone una recreación 
del África mítica invocada por los autores de la negritud caribeña (por ejemplo en Batouala de René Maran de 1921, Pigments de Léon-Gontran Damas de 1937 o Nedje de Roussan Camille de 1940), no hay en estos poemas un tono reivindicatorio de pertenencia al continente de origen. Encontramos más bien una expresión elegíaca de nostalgia por un pasado muy alejado del presente debido a la crueldad y la violencia de la historia vivida desde el corte que significó el viaje al cautiverio. La poesía adquiere a menudo un tono de "denuncia de las arbitrariedades que se cometían con los negros" (Schwartz, Las vanguardias 622), en una clara conciencia de la condición socioeconómica y política sufrida por el negro en Brasil. No obstante, no vemos aquí tampoco la voluntad de una defensa política, histórica o cultural de la raza negra en sí misma, sino un rescate de aquellos aspectos que conforman lo que el poeta considera la esencia de lo negro: un ser sufriente por la pérdida de sus raíces en la experiencia devastadora de la esclavitud, que fermenta aún en su sangre y se expresa a través del gemido lúgubre y permanente de sus danzas y de su música.

El negrismo de Bopp trasunta entonces, más que una visión del negro puro o trasplantado en la cultura del guión (afro-...), una poética del sincretismo no solo con el elemento blanco sino principalmente con el elemento indio, en una voluntad asimismo de conferir cierta unidad a su obra, ya que de esta manera Urucungo queda ligado a Cobra Norato (1931), ambos escritos desde la perspectiva antropofágica y en un impulso "esotérico", como el propio autor afirma en la carta introductoria.

\section{Obras citadas}

Bastide, Roger. Las Américas Negras. Madrid: Alianza Editorial, 1969.

-. Poetas do Brasil. São Paulo: Edusp/ Duas Cidades, 1997.

Candido, Antonio. Literatura e Sociedade. São Paulo:

Companhia Editora Nacional, 1973.

Colombres, Adolfo. "Palabra y artificio: las literaturas "bárbaras".

América Latina: Palavra, Literatura e Cultura. Ana Pizarro.

São Paulo: Editora da Unicamp, 1995. 127-167.

Depestre, René. Bonjour et adieu à la négritude. París: Robert Laffont, 1980.

Paes, José Paulo. "A ruptura vanguardista: as grandes obras". América Latina: Palavra, Literatura e Cultura. Ana Pizarro. São Paulo: Editora da Unicamp, 1995; 99-123.

Schwartz, Jorge. Las vanguardias latinoamericanas. Madrid: Ed. Cátedra, 1991.

-. Tupi or not tupí. El grito de guerra en la literatura del Brasil moderno, Brasil 19201950. De la Antropofagia a Brasilia. Valencia: IVAM Centro Julio González, 2000. 